\title{
Evaluation of the quality of life of postmenopausal osteoporotic and osteopenic women with or without fractures
}

\author{
Grażyna Bączyk ${ }^{1}$, Włodzimierz Samborski², Krystyna Jaracz ${ }^{3}$
}

\author{
${ }^{1}$ Department of Practice Nursing, Faculty of Health Sciences, Poznan University \\ of Medical Sciences, Poznan, Poland \\ ${ }^{2}$ Department of Rheumatology and Rehabilitation, Poznan University of Medical \\ Sciences, Poznan, Poland \\ ${ }^{3}$ Department of Neurological and Psychiatric Nursing, Poznan University of Medical \\ Sciences, Poznan, Poland
}

Submitted: 5 August 2014

Accepted: 1 January 2015

Arch Med Sci 2016; 12, 4: 819-827

DOI: $10.5114 /$ aoms.2015.55012

Copyright $\odot 2016$ Termedia \& Banach

\section{Abstract}

Introduction: Most studies concerned with the quality of life (QoL) of women with reduced bone mineral density (BMD) focus on patients with vertebral and non-vertebral fractures. Our objective was to evaluate QoL among patients with reduced BMD regardless of their fracture history compared to women with normal BMD.

Material and methods: Eighty-five patients in the study group were classified as osteoporotic, with BMD results measured by densitometry and expressed by T-score $\leq-2.5$ SD, 122 women were osteopenic, with $-2.5<$ T-score $\leq-1.0$ SD, and 97 subjects were assessed as normal, with T-score $>-1.0$ SD. Mean ages of women according to groups were 59.90, 57.67 and 55.68 , respectively. Assessment of life quality was conducted using the Polish version of the QUALEFFO-41 scale.

Results: The ratings in the assessment (QUALEFFO-41) of QoL were lower for osteoporotic and osteopenic women than for the normal BMD group with regard to pain $(p=0.006)$, social function $(p=0.001)$, health perception $(p=0.001)$, and mental function $(p=0.001)$. For total QUALEFFO-41 the associated factors were: secondary and higher education $(\mathrm{OR}=0.49 ; 95 \% \mathrm{Cl}$ : $0.29-0.82)$, self-perceived deformity of the back $(\mathrm{OR}=4.09 ; 95 \% \mathrm{Cl}: 1.88-$ 8.93), previous fractures $(\mathrm{OR}=2.52 ; 95 \% \mathrm{Cl}: 1.09-5.82)$, reduced height $(\mathrm{OR}=2.48 ; 95 \% \mathrm{Cl}: 1.13-5.39)$ and anxiety $(\mathrm{OR}=1.42 ; 95 \% \mathrm{Cl}: 1.21-1.66)$. Conclusions: It seems necessary to evaluate QoL of women with reduced BMD before fractures occur, to aid development of health education aiming to reduce the incidence of osteoporosis and prevent fractures.

Key words: quality of life, osteoporosis, osteopenia, QUALEFFO-41.

\section{Introduction}

An imbalance of bone tissue may lead to a reduction in bone mineral density (BMD) and, as a consequence, to the development of osteopenia and, subsequently, osteoporosis. Osteoporosis is the result of metabolic disease of the osseous system characterised by reduced bone mineral density. An increase in the incidence of osteoporosis is expected in the future, due to an aging population and increasing life

\author{
Corresponding author: \\ Grażyna Bączyk PhD \\ Department \\ of Practice Nursing \\ Faculty of Health Sciences \\ Poznan University \\ of Medical Sciences \\ 79 Dabrowskiego St \\ 60-529 Poznan, Poland \\ Phone: +4861 8546864 \\ Fax: +48 618546864 \\ E-mail: gbaczyk@ump.edu.pl
}


expectancy. Unhealthy lifestyles, including the prevalent use of stimulants, the absence of exercise and diets poor in calcium and magnesium, also contribute to the increased incidence of osteoporosis [1-4]. Postmenopausal women are at the highest risk of developing osteoporosis, since their bone mineral density is reduced as a result of a decrease in the oestrogen level [1, 5]. The improving detection of osteopenia and osteoporosis is also associated with the increase in life expectancy and the increasing population of the elderly. Fractures represent the most serious consequences of reduced bone mineral density. In many patients they cause loss of independence, aggravation of pain and a deterioration in health-related quality of life, which may be associated with functional limitations and social life restrictions $[6,7]$.

Numerous studies of osteoporotic and osteopenic women have shown that a poor quality of life $(\mathrm{QoL})$ is determined by their functional status, manifested by a poor state of the osseous system which limits physical activity, distorts body posture, causes pain and affects the mental state [6, 8-10]. These papers also indicate that the proportion of patients with osteopenia, osteoporosis and other bone diseases who assess their QoL as poor is significantly higher than among healthy persons [11-14]. While most studies concerned with the QoL of women with reduced BMD focus on patients with vertebral and non-vertebral fractures, our objective was to evaluate the QoL among patients with reduced BMD, regardless of their fracture history, compared to women with normal BMD. Our aim was to evaluate the QoL of women with reduced BMD before fractures occur in order to aid the development of health education aimed at reducing the incidence of osteoporosis and to prevent fractures.

The main aim of our study was to compare of the QoL in the domains of pain, physical functioning, social functioning, health and the perception of mental functioning in postmenopausal women with osteoporosis and osteopenia with those in women with normal BMD, independently of osteoporotic fractures. Moreover, the aim of the study was to identify factors associated with the QoL of women with reduced BMD.

\section{Material and methods}

The study group consisted of women aged 50-69 years attending the Menopause and Osteoporosis Outpatient Clinic of the Obstetric and Gynaecological Hospital of Poznan University of Medical Sciences who had been previously referred as outpatients by the patient's general practitioner for the treatment of osteoporosis. The control group consisted of women referred by their gynaecologist for prophylactic densitometry tests at the Densitometry Laboratory of the same hospital.

The main selection criterion for inclusion of women in the study group was the occurrence of either osteoporosis or osteopenia confirmed by the results of densitometric tests. By contrast, the main criterion of the control group of women was the exclusion of reduced bone mineral density.

Other significant inclusion criteria were: residence in Poznan, at least 50 years of age, lack of menstruation for at least one year and preservation of the internal genital organs.

Subjects with secondary osteoporosis, metabolic bone disease, malignant bone metastasis, hypogonadal states, osteogenesis imperfecta and those treated with glucocorticoids were excluded. Endocrine, gastrointestinal, rheumatologic and hematologic disorders were also exclusion criteria. A diagnosis of osteoarthritis in the patient's history, a current bone fracture and the existence of other diseases whose presence might influence the QoL were additional exclusion criteria.

For all the women, a BMD densitometry test was performed on the $L_{1}-L_{4}$ lumbar spines and the femoral neck, by the DXA method (dual-energy X-ray absorptiometry) using the Lunar DPX-L densitometer (Lunar Radiation Corporation, Madison, WI, USA).

In line with the BMD definition of the World Health Organization [15] and in accordance with the above-mentioned criteria, 304 women were eventually enrolled in the study:

1) 85 women in the study group were classified as osteoporotic, with BMD results measured by densitometry and expressed by T-scores $\leq-2.5$ standard deviations (SD), $\mathrm{L}_{1}-\mathrm{L}_{4}$, T-scores (mean \pm ) $-3.11 \pm 0.45$ and femoral neck T-scores (mean \pm ) $-3.10 \pm 0.44$ ), and formed group 1 .

2) 122 women were osteopenic, with $-2.5<$ T-scores $\leq-1.0 \mathrm{SD}, \mathrm{L}_{1}-\mathrm{L}_{4}$, T-scores (mean \pm ) $1.91 \pm 0.52$ and femoral neck T-scores (mean \pm ) $-1.72 \pm 0.37$ ), and formed group 2 .

3) 97 subjects were assessed as normal, with T-scores $>-1.0 \mathrm{SD}, \mathrm{L}_{1}-\mathrm{L}_{4}$, T-scores (mean \pm ) $0.16 \pm 0.69$ and femoral neck T-scores (mean \pm ) $-0.13 \pm 0.57$ ), and formed the control group 3 (Table I).

We obtained the written consent of the patients for their participation in the study, which was approved by the Ethical Review Committee at the Poznan University of Medical Sciences.

\section{Vertebral morphometry}

Among women with osteoporosis and osteopenia we assessed vertebral fractures in $L_{1}-L_{4}$ using the DXA method of vertebral fracture assessment (VFA) according to the Genant criteria [16]. 
Table I. Characteristics of women according to groups

\begin{tabular}{|c|c|c|c|c|}
\hline Variables & $\begin{array}{c}\text { Group } 1 \\
\text { Osteoporosis } \\
n=85 \\
\text { (T-score } \leq-2.5 \text { ) }\end{array}$ & $\begin{array}{c}\text { Group } 2 \\
\text { Osteopenic } \\
n=122 \\
(-2.5<\mathrm{T} \text {-score } \\
\leq-1.0)\end{array}$ & $\begin{array}{c}\text { Group } 3 \\
\text { Normal BMD } \\
n=97 \\
(\text { T-score }>-1.0)\end{array}$ & Value of $p$ \\
\hline Age, mean \pm SD [years] & $59.90 \pm 5.20$ & $57.67 \pm 4.54$ & $55.68 \pm 5.71$ & $\begin{array}{c}<0.001^{\mathrm{a}} \\
1: 2 ; 1: 3 ; 2: 3\end{array}$ \\
\hline Age at menopause, mean \pm SD [years] & $49.70 \pm 4.45$ & $48.42 \pm 5.14$ & $49.25 \pm 3.06$ & $0.135^{a}$ \\
\hline $\mathrm{BMI}$, mean $\pm \mathrm{SD}\left[\mathrm{kg} / \mathrm{m}^{2}\right]$ & $22.30 \pm 3.10$ & $24.76 \pm 4.12$ & $26.05 \pm 3.71$ & $\begin{array}{c}<0.001^{\mathrm{a}} \\
1: 2 ; 1: 3 ; 2: 3\end{array}$ \\
\hline Secondary and higher education, $n(\%)$ & $63(74.1)$ & $90(73.7)$ & $65(67.0)$ & $0.547^{b}$ \\
\hline Vocational activity, $n(\%)$ & $16(18.8)$ & $50(41.0)$ & $60(61.8)$ & $\begin{array}{l}<0.001^{\mathrm{b}} \\
1: 2 ; 1: 3\end{array}$ \\
\hline Previous fractures, $n(\%)$ & $18(21.2)$ & $23(18.8)$ & - & $0.128^{b}$ \\
\hline Reduced height $\geq 3 \mathrm{~cm}, n(\%)$ & $36(42.4)$ & $40(32.8)$ & - & $0.053^{b}$ \\
\hline Self-perceived deformity of the back, $n(\%)$ & $38(44.7)$ & $49(40.2)$ & - & $0.143^{b}$ \\
\hline $\begin{array}{l}\text { Family history of osteoporotic fractures, } \\
n(\%)\end{array}$ & $32(38)$ & $42(34.4)$ & $9(9.3)$ & $\begin{array}{c}0.004^{b} \\
1: 3 ; 2: 3\end{array}$ \\
\hline $\mathrm{L}_{1}-\mathrm{L}_{4}, \mathrm{~T}$-score, mean $\pm \mathrm{SD}$ & $-3.11 \pm 0.45$ & $-1.91 \pm 0.52$ & $-0.16 \pm 0.69$ & $\begin{array}{c}<0.001^{\text {a }} \\
1: 2 ; 1: 3 ; 2: 3\end{array}$ \\
\hline $\mathrm{L}_{1}-\mathrm{L}_{4} \mathrm{BMD}$, mean $\pm \mathrm{SD}\left[\mathrm{g} / \mathrm{cm}^{2}\right]$ & $0.8 \pm 0.08$ & $0.91 \pm 0.15$ & $1.12 \pm 0.31$ & $\begin{array}{c}<0.001^{\text {a }} \\
1: 2 ; 1: 3 ; 2: 3\end{array}$ \\
\hline Femoral neck T-score, mean \pm SD & $-3.10 \pm 0.44$ & $-1.72 \pm 0.37$ & $-0.13 \pm 0.57$ & $\begin{array}{c}<0.001^{\mathrm{a}} \\
1: 2 ; 1: 3 ; 2: 3\end{array}$ \\
\hline Femoral neck BMD, mean $\pm \mathrm{SD}\left[\mathrm{g} / \mathrm{cm}^{2}\right]$ & $0.59 \pm 0.06$ & $0.72 \pm 0.14$ & $0.86 \pm 0.07$ & $\begin{array}{c}<0.001^{a} \\
1: 2 ; 1: 3 ; 2: 3\end{array}$ \\
\hline Vertebral fractures by morphometry, $n(\%)$ & $18(21.2)$ & $12(9.8)$ & - & - \\
\hline Bisphosphonates therapy, $n$ (\%) & $60(70.6)$ & $23(18.9)$ & - & $<0.001^{b}$ \\
\hline Hormone replacement therapy, $n(\%)$ & $34(40.0)$ & $38(31.1)$ & $36(37.1)$ & $0.061^{\mathrm{b}}$ \\
\hline Calcium and vitamin D supplements, $n(\%)$ & $64(75.3)$ & $54(44.3)$ & $22(22.7)$ & $\begin{array}{c}<0.001^{\mathrm{b}} \\
1: 2 ; 1: 3 ; 2: 3\end{array}$ \\
\hline Current smoking, $n(\%)$ & $12(14.1)$ & $18(14.6)$ & $14(14.4)$ & $0.971^{b}$ \\
\hline Physical activity $1-2$ times/week, $n(\%)$ & $47(55.3)$ & $57(46.7)$ & $48(49.5)$ & $0.119^{b}$ \\
\hline Anxiety, $n$ (\%) & $17(20.0)$ & $28(22.9)$ & $22(22.7)$ & $0.124^{b}$ \\
\hline Depression, $n(\%)$ & $19(22.3)$ & $29(23.8)$ & $21(21.6)$ & $0.132^{\mathrm{b}}$ \\
\hline
\end{tabular}

${ }^{a}$ ANOVA, ${ }^{b} \chi^{2}$ test.

\section{Clinical and anthropometric parameters}

The body mass and height were measured and the body mass index was calculated. The subjects responded to questions about their sociodemographic and clinical parameters: previous fractures, reduced height $\geq 3 \mathrm{~cm}$, family history of osteoporotic fractures, date of the patient's last menstruation, as well as current smoking, current alcohol consumption and physical activity. The investigated women were also asked about any change they had observed in the shape of their back.

In accordance with the osteoporotic spine postural classification suggested by Satoh et al. [17], the subjects were asked to assess their posture (self-perceived deformity of the back): correct pos- ture or back distortion in their own opinion (rounded back, front lordosis, generalized kyphosis).

In addition, they were asked whether or not they were receiving: 1) medication associated with osteoporosis therapy; 2) hormone replacement therapy (HRT) or 3) calcium and vitamin D supplementation.

\section{FRAX-based assessment of the risk of fractures}

The FRAX method $[18,19]$ has been used to assess the 10-year probability of fracture for individual study groups. The average BMD values, evaluated for the femoral neck and clinical risk factors, were calculated. 


\section{Evaluation of anxiety and depression}

Anxiety and depression were evaluated using the Polish version of the Hospital Anxiety and Depression Scale (HADS) [20]. This consists of a total of 14 questions, with the answers being scored from 0 to 3 . The total maximum number of points is 21 for anxiety and 21 for depression.

\section{Evaluation of quality of life}

Assessment of life quality was conducted using the Polish version of the QUALEFFO-41 scale $[21,22]$. This scale is designed to evaluate the QoL with respect to physical, social and mental function as well as pain and is assessed on a scale of 0 to 100 , with 0 indicating the highest QoL and 100 the lowest.

\section{Statistical analysis}

Differences between the groups with regard to QUALEFFO-41, as well as to factors determining the QoL within the groups, were analysed using Student's $t$-test and analysis of variance (ANOVA) for independent and dependent data. Significant differences in comparisons, taking into account the large number of categories, were investigated using Bonferroni's, Dunnett's and Tukey's post hoc analyses depending on the number of groups and the distribution of the dependent variables. Determination of predictive factors for QoL was performed using stepwise logistic regression analysis and the Akaike information criterion (AIC) for model assessment. The cut-off for the QUALEFFO-41 scale was set at the median for each area and the overall score. Scores equal to the median, or lower, indicated a high QoL, while scores higher than the median pointed to a low QoL.

The regression analysis model used all the variables with a potential impact on QoL as predictors. The following were quantitative continuous variables: age, $\mathrm{BMI}\left(\mathrm{kg} / \mathrm{m}^{2}\right)$, anxiety and depression. The other variables were considered as categorical (0-1): education, work status, previous fractures, reduced height, self-perceived deformity of the back, current smoking, physical activity, use of bisphosphonates, use of HRT and the use of calcium and vitamin D supplements.

Statistical analysis was performed using SPSS for Windows Version 20 (SPSS INC., Chicago, IL, USA).

\section{Results}

The age of participants ranged from 50 to 69 years. The mean ages (in years) of the osteoporotic, osteopenic and normal women were $59.90 \pm$ $5.20,57.67 \pm 4.54$ and $55.68 \pm 5.71$ respectively. The patients with osteoporosis were significantly older than the women in the other two groups.
Most women in the study had a secondary or higher education and were married. The distribution of these variables did not differ between the study groups. On the other hand, a difference was found with regard to work status. A majority of the osteoporotic and osteopenic patients were retired, or received a disability pension, while most of the women with a normal BMD were vocationally active.

Analysis of the anthropometric and clinical data revealed that the average age at menopause did not differ between the study groups. The average body mass index (BMI) was $22.30 \mathrm{~kg} / \mathrm{m}^{2}$ in the osteoporosis group, $24.76 \mathrm{~kg} / \mathrm{m}^{2}$ in the osteopenia group and $26.05 \mathrm{~kg} / \mathrm{m}^{2}$ in the normal BMD group. Significant differences, with regard to average $\mathrm{BMI}$ values, were found between osteoporotic and osteopenic women on the one hand, and participants with a normal BMD on the other $(p<0.001)$.

Previous fractures, reduced height and self-perceived deformity of the back were recorded only in the osteoporotic and osteopenic groups, with no significant differences found in this respect. A family history of osteoporotic fractures was significantly more frequent among both those with osteoporosis and those with osteopenia (reported by ca. $30 \%$ of them) than among women with a normal BMD.

\section{0-year probability of fracture risk for women with osteoporosis}

Women with osteoporosis aged between 65 and 69 and with two risk factors observed had a fracture probability of $30 \%$, while for those with 3 factors observed the fracture risk was $41 \%$.

\section{0-year probability of fracture risk for women with osteopenia}

Women with osteopenia aged between 65 and 69 and with 1 factor observed had a fracture probability of $14 \%$, whereas for women with 2 factors the fracture risk increased to $20 \%$.

\section{0-year probability of fracture risk for women with normal BMD}

For women aged between 65 and 69 and with no clinical factors the risk of fracture was only $5.9 \%$, and for those with 1 factor observed it was $8.5 \%$. None of the women in this age group had 2 or more fracture risk factors.

Most osteoporotic and osteopenic women were taking some form of active treatment (hormone replacement therapy), bisphosphonates, calcium supplementation with vitamin D). Bisphosphonates were administered to $70.6 \%$ of the osteoporotic women, $10.6 \%$ received both bisphosphonates and HRT, and $18.9 \%$ of osteopenic women 
received bisphosphonates only. Differences were not found with regard to taking HRT, being reported by $40.0 \%$ of osteoporotic women, $31.1 \%$ of the osteopenic women and $37.1 \%$ of the women with normal BMD. $75.3 \%$ of women with osteoporosis, $44.3 \%$ of the women with osteopenia and $22.7 \%$ of the women with a normal BMD had been receiving daily doses of $500 \mathrm{mg}$ of calcium and 400 IU of vitamin D.

Differences were not found with regard to smoking, physical activity, anxiety and depression symptoms. The latter were reported by approximately $20 \%$ of all participants (Table I).

\section{BMD results}

The average BMD values and the average T-scores for the lumbar spine and femoral neck significantly differed, at the level of $p<0.001$, for osteoporotic patients, osteopenic patients and women with a normal BMD (Table I).

\section{Quality of life}

The survey results demonstrated that the QoL in postmenopausal women with reduced BMD was inferior to that of the group with a normal BMD. The ratings in the QUALEFFO-41 assessment of the QoL were lower for osteoporotic and osteopenic women than for the group of normal BMD women, with regard to pain $(p=0.006)$, social function $(p=0.001)$, health perception $(p=$ $0.001)$, and mental function ( $p=0.001)$ (Table II).

Because the women with osteoporosis were older than the women with osteopenia and the women in the control group, the general QoL was assessed with age taken into consideration. The mean value of the general QoL for women with osteoporosis aged between 50 and 54 was 22.65, for women aged between 55 and 59 it was 30.50, for women aged between 60 and 64 it was 30.95, and for women aged between 65 and 69 it was 31.49. The differences between the group of wom- en aged 50-54 and the remaining age groups were statistically significant at the significance level of $p=0.04$.

The mean value of general QoL was 23.39 for women with osteopenia aged between 50 and 54, 24.20 for women aged between 55 and 59, 28.67 for women aged 60-64, and 31.57 for women aged 65-69. The difference between the group of women aged 50-54 and 65-69 was statistically significant at the significance level of $p=0.04$.

No differences between age groups for the mean values of general QoL were observed for the women with normal BMD.

Table III shows the QUALEFFO-41 results obtained by comparing the osteoporotic and osteopenic women with, or without, vertebral fractures. Thirty women with vertebral fractures were found: 26 with mild and 4 with moderate fractures (3 osteoporotic women and 1 osteopenic woman). In the data analysis, moderate fractures were pooled with mild vertebral fractures. Among the osteoporotic women a significant difference was found between those with fractures and those with no fractures for the following domains: pain $(p=0.044)$, physical function $(p=0.012)$ and total QUALEFFO-41 ( $p=0.022$ ). Among the osteopenic women a significant difference was found between those with fractures and those with no fractures for the following domains: pain ( $p=$ $0.03)$ and total QUALEFFO-41 $(p=0.02)$.

Table IV shows the factors associated with QoL for osteoporotic and osteopenic women by logistic regression analysis, using the QUALEFFO-41. Regarding the pain domain, the associated factors were: secondary and higher education $(O R=0.39$; 95\% Cl: 0.25-0.63), reduced height $(\mathrm{OR}=2.24$; $95 \% \mathrm{Cl}: 1.04-4.84)$. For the physical function domain, the associated factors were: secondary and higher education $(\mathrm{OR}=0.43 ; 95 \% \mathrm{Cl}$ : 0.25-0.75), self-perceived deformity of the back $(O R=4.15$; $95 \% \mathrm{Cl}: 1.97-8.71)$, reduced height $(\mathrm{OR}=2.68$; $95 \% \mathrm{Cl}: 1.25-5.75)$ and $\mathrm{BMI} \geq 25 \mathrm{~kg} / \mathrm{m}^{2}(\mathrm{OR}=$

Table II. Comparison of QoL as assessed by QUALEFFO-41, between osteoporotic women, osteopenic women and women with normal BMD

\begin{tabular}{|c|c|c|c|c|}
\hline QUALEFFO-41 domains & $\begin{array}{c}\text { Group } 1 \\
\text { Osteoporosis } \\
n=85 \\
\text { (T-score } \leq-2.5 \text { ) } \\
\text { Mean } \pm \text { SD }\end{array}$ & $\begin{array}{c}\text { Group } 2 \\
\text { Osteopenic } \\
n=122 \\
(-2.5<\text { T-score } \leq-1.0) \\
\text { Mean } \pm \text { SD }\end{array}$ & $\begin{array}{c}\text { Group } 3 \\
\text { Normal BMD } \\
n=97 \\
\text { (T-score }>-1.0 \text { ) } \\
\text { Mean } \pm \text { SD }\end{array}$ & Value of $p$ \\
\hline Pain & $42.1 \pm 29.9$ & $35.1 \pm 24.2$ & $18.9 \pm 26.1$ & $0.006(1: 3,2: 3)$ \\
\hline Physical function & $23.4 \pm 15.3$ & $22.9 \pm 18.2$ & $13.0 \pm 12.9$ & $0.001(1: 3,2: 3)$ \\
\hline Social function & $46.4 \pm 22.3$ & $43.9 \pm 20.2$ & $36.9 \pm 18.0$ & $0.002(1: 3,2: 3)$ \\
\hline General health perception & $60.9 \pm 24.3$ & $56.5 \pm 20.9$ & $46.1 \pm 18.9$ & $0.001(1: 3,2: 3)$ \\
\hline Mental function & $41.1 \pm 13.8$ & $38.8 \pm 16.1$ & $31.9 \pm 14.9$ & $0.001(1: 3,2: 3)$ \\
\hline Total QUALEFFO-41 score & $28.9 \pm 11.8$ & $27.1 \pm 11.8$ & $19.8 \pm 10.1$ & $0.001(1: 3,2: 3)$ \\
\hline
\end{tabular}


Table III. Comparison of QoL in the QUALEFFO-41, between osteoporotic and osteopenic women grouped according to the presence or absence of vertebral fractures assessed by morphometry

\begin{tabular}{|lcccccc|}
\hline $\begin{array}{l}\text { QUALFFF-41 } \\
\text { domains }\end{array}$ & \multicolumn{3}{c}{$\begin{array}{c}\text { Osteoporotic group } \\
\text { Vertebral fractures }\end{array}$} & \multicolumn{3}{c|}{$\begin{array}{c}\text { Osteopenic group } \\
\text { Vertebral fractures }\end{array}$} \\
\cline { 2 - 7 } & $\begin{array}{c}\text { No. }(n=67) \\
\text { Mean } \pm \text { SD }\end{array}$ & $\begin{array}{c}\text { Yes }(n=18) \\
\text { Mean } \pm \text { SD }\end{array}$ & Value of $p$ & $\begin{array}{c}\text { No }(n=110) \\
\text { Mean } \pm \text { SD }\end{array}$ & $\begin{array}{c}\text { Yes }(n=12) \\
\text { Mean } \pm \text { SD }\end{array}$ & Value of $p$ \\
\hline Pain & $38.8 \pm 29.7$ & $54.4 \pm 28.3$ & 0.044 & $33.9 \pm 23.9$ & $36.5 \pm 28.1$ & 0.03 \\
\hline Physical function & $22.5 \pm 13.4$ & $26.7 \pm 21.0$ & 0.012 & $22.7 \pm 14.8$ & $23.7 \pm 20.7$ & 0.241 \\
\hline Social function & $45.2 \pm 22.7$ & $46.1 \pm 25.9$ & 0.183 & $44.0 \pm 22.3$ & $45.3 \pm 20.0$ & 0.587 \\
\hline $\begin{array}{l}\text { General health } \\
\text { perception }\end{array}$ & $60.2 \pm 23.4$ & $63.4 \pm 28.2$ & 0.621 & $54.9 \pm 20.5$ & $55.8 \pm 20.7$ & 0.601 \\
\hline Mental function & $40.3 \pm 14.0$ & $44.0 \pm 12.7$ & 0.323 & $37.8 \pm 16.1$ & $40.4 \pm 13.9$ & 0.342 \\
\hline $\begin{array}{l}\text { Total QUALEFFO-41 } \\
\text { score }\end{array}$ & $28.0 \pm 11.1$ & $34.3 \pm 14.9$ & 0.022 & $25.3 \pm 12.2$ & $30.4 \pm 11.4$ & 0.02 \\
\hline
\end{tabular}

The quality of life is assessed on a scale of 0 to 100, with 0 indicating the highest quality of life and 100 indicating the lowest quality of life.

Table IV. Variables associated with QUALEFFO-41 domains in women with reduced BMD evaluated by stepwise multiple logistic regression analysis $(n=207)$

\begin{tabular}{|c|c|c|c|c|}
\hline QUALEFFO-41 domains & Variables & Value of $p$ & OR & $95 \% \mathrm{Cl}$ \\
\hline \multirow[t]{2}{*}{ Pain $>35.0$} & Secondary and higher education & 0.001 & 0.39 & $0.25-0.63$ \\
\hline & Reduced height & 0.04 & 2.24 & $1.04-4.84$ \\
\hline \multirow[t]{4}{*}{ Physical function > 16.7} & Secondary and higher education & 0.003 & 0.43 & $0.25-0.75$ \\
\hline & $\mathrm{BMI} \geq 25 \mathrm{~kg} / \mathrm{m}^{2}$ & 0.001 & 1.19 & $1.07-1.34$ \\
\hline & Reduced height & 0.01 & 2.68 & $1.25-5.75$ \\
\hline & Self-perceived deformity of the back & 0.0001 & 4.15 & $1.97-8.71$ \\
\hline \multirow[t]{4}{*}{ Social function $>42.5$} & Secondary and higher education & 0.002 & 0.47 & $0.25-0.75$ \\
\hline & $\mathrm{BMI} \geq 25 \mathrm{~kg} / \mathrm{m}^{2}$ & 0.03 & 1.12 & $1.01-1.24$ \\
\hline & Physical activity & 0.02 & 0.43 & $0.22-0.87$ \\
\hline & Self-perceived deformity of the back & 0.001 & 3.61 & $1.75-7.46$ \\
\hline \multirow{3}{*}{$\begin{array}{l}\text { General health } \\
\text { perception }>50\end{array}$} & Secondary and higher education & 0.001 & 0.45 & $0.28-0.72$ \\
\hline & Bisphosphonates therapy & 0.01 & 0.41 & $0.23-0.71$ \\
\hline & Reduced height & 0.01 & 2.67 & $1.26-5.66$ \\
\hline \multirow[t]{5}{*}{ Mental function > 38.9} & HRT & 0.02 & 0.49 & $0.27-0.89$ \\
\hline & Reduced height & 0.008 & 2.73 & $1.30-5.74$ \\
\hline & Self-perceived deformity of the back & 0.02 & 2.34 & $1.14-4.77$ \\
\hline & Anxiety & 0.001 & 1.73 & $1.35-2.23$ \\
\hline & Depression & 0.025 & 1.42 & $1.05-1.93$ \\
\hline \multirow{6}{*}{$\begin{array}{l}\text { Total QUALEFFO-41 score } \\
>23.9\end{array}$} & Secondary and higher education & 0.006 & 0.49 & $0.29-0.82$ \\
\hline & Vertebral fractures & 0.02 & 1.29 & $1.02-1.62$ \\
\hline & Reduced height & 0.02 & 2.48 & $1.13-5.39$ \\
\hline & Previous fractures & 0.03 & 2.52 & $1.09-5.82$ \\
\hline & Anxiety & 0.001 & 1.42 & $1.21-1.66$ \\
\hline & Self-perceived deformity of the back & 0.001 & 4.09 & $1.88-8.93$ \\
\hline
\end{tabular}

$O R$ - Odds ratio, $\mathrm{Cl}$ - confidence interval. Nagelkerke $R^{2}=31.6$ (Pain); Nagelkerke $R^{2}=28.9$ (Physical function); Nagelkerke $R^{2}=40.1$ (Social function); Nagelkerke $R^{2}=42.5$ (General health perception); Nagelkerke $R^{2}=39.3$ (Mental function); Nagelkerke $R^{2}=45.1$ (Total QUALEFFO-41). 
1.19; $95 \% \mathrm{Cl}: 1.07-1.34)$. For social function domain the associated factors were: secondary and higher education $(\mathrm{OR}=0.47 ; 95 \% \mathrm{Cl}: 0.25-0.75)$, physical activity $(\mathrm{OR}=0.43 ; 95 \% \mathrm{Cl}$ : $0.22-0.87)$, self-perceived deformity of the back $(O R=3.62$; $95 \% \mathrm{Cl}: 1.75-7.46)$ and $\mathrm{BMI} \geq 25 \mathrm{~kg} / \mathrm{m}^{2}(\mathrm{OR}=$ $1.12 ; 95 \% \mathrm{Cl}: 1.01-1.24)$. For the general health perception, the associated factors were: secondary and higher education $(\mathrm{OR}=0.45 ; 95 \% \mathrm{Cl}$ : 0.28-0.72), bisphosphonates therapy (OR $=0.41$; $95 \% \mathrm{Cl}: 0.23-0.71)$ and reduced height $(\mathrm{OR}=$ 2.68; $95 \% \mathrm{Cl}: 1.26-5.66)$. For the mental function domain the associated factors were: use of HRT $(\mathrm{OR}=0.49 ; 95 \% \mathrm{Cl}: 0.27-0.89)$, reduced height $(\mathrm{OR}=2.73 ; 95 \% \mathrm{Cl}: 1.30-5.74)$, self-perceived deformity of the back $(\mathrm{OR}=2.34 ; 95 \% \mathrm{Cl}: 1.14-$ 4.77), anxiety (OR $=1.53 ; 95 \% \mathrm{Cl}: 1.35-2.23)$ and depression $(\mathrm{OR}=1.33 ; 95 \% \mathrm{Cl}: 1.05-1.93)$. Finally, for the total QUALEFFO-41 score, the associated factors were: secondary and higher education $(\mathrm{OR}=0.49 ; 95 \% \mathrm{Cl}: 0.29-0.82)$, vertebral fractures $(\mathrm{OR}=1.29 ; 95 \% \mathrm{Cl}: 1.02-1.62)$, self-perceived deformity of the back $(\mathrm{OR}=4.09 ; 95 \% \mathrm{Cl}: 1.88-8.93)$, previous fractures $(\mathrm{OR}=2.52 ; 95 \% \mathrm{Cl}: 1.09-5.82)$, reduced height $(\mathrm{OR}=2.48 ; 95 \% \mathrm{Cl}: 1.13-5.39)$ and anxiety $(\mathrm{OR}=1.42 ; 95 \% \mathrm{Cl}: 1.21-1.66)$. All these finding are shown in Table IV.

\section{Discussion}

Evaluation of the QoL of women with osteoporosis, osteopenia and normal bone mineral density, with and without a history of osteoporotic fractures, was conducted using the Polish version of the QUALEFFO-41 scale.

This scale is generally used for osteoporotic patients with vertebral fractures. However, in clinical trials the scale is also used in the assessment of osteoporotic patients without vertebral fractures, especially when BMD measurements were made in the lumbar spine. Our earlier studies broadened the use of the scale, not only in patients with vertebral fractures but also in patients with reduced bone mineral density measured at the lumbar spine, with and without vertebral fractures [22].

The findings of that study showed that the QoL among osteoporotic and osteopenic women was significantly lower with regard to all domains of the QUALEFFO-41 scale than the QoL among women with normal BMD. One possible factor differentiating the QoL score, in the groups studied, was the higher mean age of patients with osteoporosis and osteopenia than of patients with a normal BMD. The effect of age on the QoL was analysed in an earlier study [6]. Other studies have confirmed the relevance of age to declining QoL in the area of physical functioning, which significantly limits physical activity. Older women are afraid of falls and their possible consequences in the form of fractures [23, 24].
Similar results, suggesting significantly lower QoL among women with reduced BMD compared to subjects with normal BMD scores, were obtained in numerous studies using the QUALEFFO scale. For instance, Ferreira et al. [12] found that QoL among osteoporotic women was lower than in the control group with regard to pain, social function and general perception of health. The effect of osteoporosis on QoL was also assessed in several other studies. Bianchi et al. [23] employed the QUALEFFO-41 scale to compare QoL among patients with and without osteoporotic fractures and among women with normal BMD. This study revealed that the QoL was lower by $41 \%$ with respect to pain, general perception of health and overall QoL, regardless of fracture occurrence. The proportion of women with a low QoL in the control group was $11 \%$. Romagnoli et al. [6] found a low QoL with respect to perception of health and mental function among osteoporotic participants, regardless of the incidence of fractures. The above findings, as well as the results of the present study, suggest that osteoporotic and osteopenic patients suffer from low QoL, especially in the physical and psychological and social domains. The awareness of a reduced BMD value and the risk of future fractures exerts a negative effect on the subjective perception of QoL.

Our women with osteoporosis and osteopenia were grouped according to the presence or absence of vertebral fractures assessed by morphometry. The results of the present study indicate that the overall QoL among women with vertebral fractures was significantly lower than that among participants without such vertebral fractures.

Other authors present findings which are consistent with ours. For example, Abourazzak et al. [9] assessed factors influencing QoL among Moroccan women with osteoporosis and vertebral deformity compared to those without $(p=0.03)$ and a history of non-vertebral fractures $(p=0.006)$.

Factors associated with a low QoL are quoted in numerous studies. Most of the results reported are consistent with ours. The variables include: high $\mathrm{BMI}$, vertebral fractures, reduced height, previous fractures, depression, anxiety and reduced BMD. In the studies of Romagnoli et al. [6] and Hallberg et al. [10], overweight osteoporotic women obtained poor scores with regard to QoL. Similarly, Ferreira et al. [12] found that obese osteoporotic women scored significantly higher (indicating a lower QoL) in the majority of QUALEFFO-41 domains, the trend being most pronounced in relation to both physical and mental functions.

Kessenich et al. [25] found, surprisingly, that reduced BMD, Colles fractures, femoral neck fractures, physical activity, financial status and age were not significant factors in the assessment of life quality. Miyakoshi et al. [24], in their study among Japa- 
nese women, revealed a negative correlation between physical and mental function and reduced BMD. Ferreira et al. [12] revealed that factors such as a high BMI and a sedentary lifestyle represented the variables most frequently pointing to low QoL with regard to pain, physical and mental function. Pain correlated with the following variables: BMI $\geq 25 \mathrm{~kg} / \mathrm{m}^{2}(\mathrm{OR}=2.32)$ and sedentary lifestyle $(\mathrm{OR}=3.12)$. A factor related to a low assessment of physical function was $B M I \geq 25 \mathrm{~kg} / \mathrm{m}^{2}(\mathrm{OR}=2.41)$. Their study did not show a correlation between social function and the factors analysed.

The results of the present study and numerous findings of other researchers indicate that the overall QoL among women with a deformity of the back was significantly lower than that among participants without such a deformity. The low QoL scores among women with deformity of the back were related to physical and social function as well as to overall QoL [11, 23, 24]. Miyakoshi et al. [24] found a significantly inferior QoL with regard to pain during daily life activities among women with postural defects, compared to participants with a normal body posture. The degree of spine mobility was a factor exerting a strong effect on the evaluation of QoL among osteoporotic women with deformity of the back. Other researchers have demonstrated that the number of fractured vertebrae is a significant prognostic factor of the poor ability to walk and also that elderly osteoporotic women with kyphosis had a severely limited ability to walk and climb stairs, which contributed to their inferior overall QoL [26]. Other authors report that vertebral fractures and kyphosis represent hidden causes of osteoporotic back pain which affect balance and functional capacity [10, 27, 28]. Adachi et al. [29] recorded significantly inferior QoL with respect to physical function among women suffering pelvic and femoral neck fractures, compared to participants with fractures of distal epiphyses of the radius and ulna. Other authors have found that the main characteristics determining low QoL were decreased height, deformity of the back, past fractures, elevated FSH level in the blood, anxiety and depression [13].

The findings of numerous authors not only indicate factors associated with low assessment of QoL but also identify variables correlating with high QoL The present study, as well as that of Moriyama et al. [30], showed a positive correlation between physical activity and QoL Our findings, and those of Abourazzak et al. [9], revealed a significant correlation between QoL and higher education, while Kessenich et al. [25] did not find such a correlation. The present study indicates that, for the perception of general health, one associated factor was the use or non-use of bisphosphonates $(\mathrm{OR}=0.41)$. According to Iwamoto et al. [31], alendronate rapidly reduced back pain and improved QoL in postmenopausal women with osteoporosis. However, Sezer et al. [32] did not find a correlation between the QoL, measured using the QUALEFFO-41 scale, and the manner of osteoporosis treatment. Perhaps it affects this lack of good adherence is a medical recommendations that patients treated for osteoporosis [33]. The present authors, as well as Ferreira et al. [12], found that a positive self-perception of one's health and a high overall QoL were more frequent among professionally active participants. Vocational activity frequently improves patients' self-confidence, by providing them with a sense of being a productive person. The use of cognitive functions in professional work reduces anxiety, worry and fear of the occurrence of disease. Moreover, professional activity leads to independence, enhances well-being and improves QoL.

According to Ferreira et al. [12], perimenopausal women should be encouraged to prevent BMD reduction and fractures by preventing falls and avoiding physical overload of the locomotor system, all of which will contribute to the maintenance of health and a high QoL.

Certain limitations of this study should be highlighted. The assessment of vertebral fractures was performed only in the lumbar region of the spine $\left(L_{1}-L_{4}\right)$. Examination of the mid-thoracic area and the thoracolumbar junction would also be useful. In addition, vertebral fractures were assessed using the DXA method only. An X-ray examination as confirmation of the presence of a fracture would be needed.

In conclusion, although most studies concerned with the QoL of women with reduced BMD focus on patients with vertebral and non-vertebral fractures, it seems necessary to evaluate the QoL before such fractures occur. Such an approach might serve to identify the factors determining QoL, which would aid in the development of customised preventive programmes, appropriate support and medical care for women with reduced BMD. It is important to develop customised preventive, as well as therapeutic and rehabilitative, programmes for premenopausal, menopausal and postmenopausal women. These preventive programmes should include education and enhance motivation to perform regular exercise to maintain an appropriate weight as well as the strength of muscles and bones, thereby reducing the incidence of fractures and improving overall well-being.

\section{Acknowledgments}

We thank Professor Geoffrey Shaw for his linguistic consultation of the paper. Supported by a grant from the State Committee for Scientific Research in Poland.

\section{Conflict of interest}

The authors declare no conflict of interest. 


\section{References}

1. Riggs BL, Khosla S, Melton U. A unitary model for involutional osteoporosis: estrogen deficiency causes both types I and II osteoporosis in postmenopausal women and osteoporosis in postmenopausal women and contributes to bone 1055 in aging men. J Bone Miner Res 1998; 13: 763-73.

2. Elshal MF, Bernawi AE, Al-Ghamdy MA, Jalal JA. The association of bone mineral density and parathyroid hormone with serum magnesium in adult patients with sickle-cell anaemia. Arch Med Sci 2012; 8: 270-6.

3. Bączyk G, Opala T, Kleka P, Chuchracki M. Multifactorial analysis of risk factors for reduced bone mineral density among postmenopausal women. Arch Med Sci 2012; 8: 332-41.

4. Anagnostis P, Vakalopoulou S, Charizopoulou M, et al. Is there any association between leptin levels and bone mineral density in haemophiliac men? Arch Med Sci 2013; 9: 459-65.

5. Sowińska-Przepiera E, Syrenicz A, Friebe Z, et al. Pvull and Xbal polymorphism of estrogen receptor-alpha and the results of estroprogestagen therapy in girls with functional hypothalamic amenorrhea - preliminary study. Arch Med Sci 2012; 8: 841-7.

6. Romagnoli E, Carnevale V, Nofroni I, et al. Quality of life in ambulatory postmenopausal women: the impact of reduced bone mineral density and subclinical vertebral fractures. Osteoporos Int 2004; 15: 975-80.

7. Cichocka-Jarosz E, Brzyski P, Świebocka E, et al. Health-related quality of life in Polish adolescents with Hymenoptera venom allergy treated with venom immunotherapy. Arch Med Sci 2012; 8: 1076-82.

8. Lips P, van Schoor NM. Quality of life in patients with osteoporosis. Osteoporos Int 2005; 16: 447-55.

9. Abourazzak FE, Allali F, Rostom S, et al. Factors influencing quality of life in Moroccan postmenopausal women with osteoporotic vertebral fracture by ECOS 16 questionnaire. Health Qual Life Outcomes 2009; 7: 23.

10. Hallberg I, Bachrach-Lindstrom M, Hammerby S, et al. Health-related quality of life after vertebral or hip fracture: a seven-year follow-up study. BMC Musculoskelet Disord 2009; 10: 135.

11. Oleksik AM, Lips P, Dawson A, et al. Health-Related Quality of Life (HRQOL) in postmenopausal women with low BMD with or without prevalent vertebral fractures. J Bone Miner Res 2000; 15: 1384-92.

12. Ferreira NO, Arthuso M, Silva R, et al. Quality of life in women with postmenopausal osteoporosis: correlation between QUALEFFO 41 and SF-36. Maturitas 2009; 62: 85-90.

13. Bączyk G, Chuchracki M, Opala T. Effect of selected socio-demographic, clinical and biochemical factors on self-reported quality of life among post-menopausal women with osteoporosis. Ann Agric Environ Med 2013; 20: 843-8.

14. Molski P, Kruczyński J, Molski A, Molski S. Manual lymphatic drainage improves the quality of life in patients with chronic venous disease: a randomized controlled trial. Arch Med Sci 2013; 9: 452-8.

15. World Health Organization Study Group. Assessment of fracture risk and its application to screening for post-menopausal osteoporosis. In WHO Technical Report Series. No,843 WHO, Geneva, 1994.

16. Genant HK, Wu CY, Yan Kuijk. Vertebral fracture assessment using a semiquantitative technique. J Bone Miner Res 1993; 8: 1137-48.
17. Satoh K, Kasama F, Itoi E, et al. Clinical features of spinal osteoporosis: spinal deformity and pertinent back pain. Contemp Orthop 1988; 16: 23-30.

18. Kanis JA, McCloskey EV, Johansson H. National Osteoporosis Guideline Group. Case findings for the management of osteoprosis with FRAX - assessment and intervention thresholds for the UK. Osteoporos Int 2008; 19: 1395-408.

19. Kanis JA. FRAX Polish population: http://shef.ac.uk/FRAX/

20. Watrowski R, Rohde A. Validation of the Polish version of the Hospital Anxiety and Depression Scale in three populations of gynecologic patients. Arch Med Sci 2014; 10: 517-24.

21. Lips P, Cooper C, Agnusdei D, et al. Quality of life in patients with vertebral fractures: validation of the Quality of Life Questionnaire of the European Foundation for Osteoporosis (QUALEFFO), Working Party for Quality of Life of the European Foundation for Osteoporosis. Osteoporos Int 1999; 10: 150-60.

22. Baczyk G, Opala T, Kleka P. Quality of life in postmenopausal women with reduced bone mineral density: psychometric evaluation of the Polish version of QUALEFFO-41. Arch Med Sci 2011; 7: 476-85.

23. Bianchi ML, Orsini MR, Saraifoger S, Ortolani S, Radaelli G, Betti S. Quality of life in post-menopausal osteoporosis. Health Qual Life Outcomes 2005; 3: 78-84.

24. Miyakoshi N, Itoi E, Kobayashi M, Kodama H. Impact of postural deformities and spinal mobility on quality of life in postmenopausal osteoporosis. Osteoporos Int 2003; 14: 1007-12.

25. Kessenich CR, Guyatt GH, Rosen CJ. Health-related quality of life and participation in osteoporosis clinical trials. Calcif Tissue Int 1998; 62: 189-92.

26. Oleksik AM, Ewing S, Shen W, van Schoor NM, Lips P. Impact of incident vertebral fractures on health related quality of life (HRQOL) in postmenopausal women with prevalent vertebral fractures. Osteoporos Int 2005; 16: 861-70.

27. Huang C, Ross PD, Wasnich RD. Vertebral fractures and other predictors of physical impairment and health care utilization. Arch Int Med 1996; 156: 2469-75.

28. Silverman SL. Quality-of- life issues in osteoporosis. Curr Rheumatol Reports 2005; 7: 189-92.

29. Adachi JD, loannidis G, Berger C, et al. The influence of osteoporotic fractures on Health-Related Quality of Life in community-dwelling men and women across Canada. Osteoporos Int 2001; 12: 903-8.

30. Moriyama CK, Oneda B, Bernardo FR, et al. A randomized, placebo-controlled trial of the effect of physical exercise and estrogen therapy on health-related quality of life in postmenopausal women. Menopause 2008; 15: 613-8.

31. Iwamoto J, Makita K, Sato T, Takeda T, Matsumoto H. Alendronate is more effective than elcatonin in improving pain and quality of life in postmenopausal women with osteoporosis. Osteoporos Int 2011; 22: 2735-42.

32. Sezer N, Tomruk-Sutbeyaz S, Kibar S, Koseoglu F, Aras M. Determinants of quality of life in postmenopausal osteoporosis. FTR Bil Der JPMR Sci 2009; 12: 19-25.

33. Sewerynek E, Horst-Sikorska H, Wioletta Stępień-Kłos $\mathrm{W}$, et al. The role of counselling and other factors in compliance of postmenopausal osteoporotic patients to alendronate 70 therapy. Arch Med Sci 2013; 9: 288-96. 